\title{
Multiple sclerosis among the United Kingdom-born children of immigrants from the West Indies
}

\author{
MARTA ELIAN, GEOFFREY DEAN \\ From the Regional Centre for Neurology and Neurosurgery, Oldchurch Hospital, Romford, UK and the \\ Medico-Social Research Board, Dublin, Republic of Ireland
}

SUMMARY Multiple sclerosis has been reported to be very uncommon in the West Indies. In previous studies immigrants from the West Indies resident in Greater London had only one-eighth the likelihood of being diagnosed in hospital as having multiple sclerosis compared with those born in the United Kingdom. No studies of the incidence and prevalence of multiple sclerosis were available for London or South East England but there is evidence that it is much the same as occurs in Ireland. In the age groups studied the United Kingdom-born children of West Indian immigrants had an incidence and prevalence of probable multiple sclerosis of the same order as has been reported in Northern Ireland and in the Irish Republic. Although there is evidence that genetic factors play a part, our findings are strong evidence that the cause of the disease is mainly environmental and is therefore potentially preventable.

Multiple sclerosis has been reported to be very uncommon in the West Indies, for instance in Jamaica, ${ }^{12}$ in Asia, for example among the Indian and Pakistani people, and in Africa among the black Africans. ${ }^{34}$ In Greater London and the West Midlands, during the years 1960-72, West Indian immigrants had only one-eighth the chance of being hospitalised with a first diagnosis of multiple sclerosis as the United Kingdom-born. ${ }^{56}$ The present study was to ascertain if the children of West Indian immigrants, born in England, keep the low incidence of multiple sclerosis of their parents or if they acquired the high incidence that occurs in England.

\section{Method}

The population at risk

At the 1971 census a question was included on birthplace and birthplace of parents. ${ }^{7}$ At the 1981 census the birthplace of parents was omitted but the birthplace of the head of household was available and this information was included in a survey of persons by birthplace of head of household. ${ }^{8}$ The heads of households' birthplace cannot be equated directly with the ethnic origin because the New Commonwealth-born heads of household will include some people (very few among those from the West Indies) of British origin who were born in the New Commonwealth (NC)

Address for reprint requests: Dr G Dean, Medico-Social Research Board, 73 Lower Baggot St. Dublin 2, Eire

Received II February 1986 and in revised form 5 June 1986. Accepted 19 June 1986 countries. A further survey undertaken in 1981 was the Labour Force Survey based on a small $1 / 2 \%$ sample only. 9

An estimate of the United Kingdom-born population with NC-born parents can be obtained by bringing forward the 1971 census figures to 1981 . This has been done for the United Kingdom-born with NC American (West Indian) parents resident in Greater London, presuming that few have died and that there is a balance in this population between those who had left and those who have entered Greater London between 1971 and 1981. The census data of the population of United Kingdom-born children of NC American (West Indian) parents brought forward from the 1971 census to 1981 can be compared with the survey based on the head of the household from the 1981 census, and on the small sample Labour Force Survey 1981 (table 1). The comparison shows that bringing forward the 1971 census data to 1981 gives a fair approximation of this population between the ages of 15 and 29 years.

\section{The patients}

We searched for the patients for the nine years between 1976, when the study started, and 1984. Ethnic Asians and Africans diagnosed as having multiple sclerosis can generally be detected in their case records by their Asian or African names. West Indians, whether immigrants or United Kingdom-born, have usually English, Scottish or Irish names, and therefore cannot be detected by their names. While finding the immigrants in previous studies ${ }^{56}$ was time-consuming but relatively easy as birthplace of immigrants was generally recorded somewhere in the patients' records, it was difficult to detect from the hospital records the West Indian patients who were born in England. We asked and obtained the help of many informants, particularly the consultants, registrars and other medical and secre- 
Table 1 A comparison of three methods of estimating the United Kingdom-born children of New Commonwealth American (West Indian)-born parents resident in Greater London in 1981

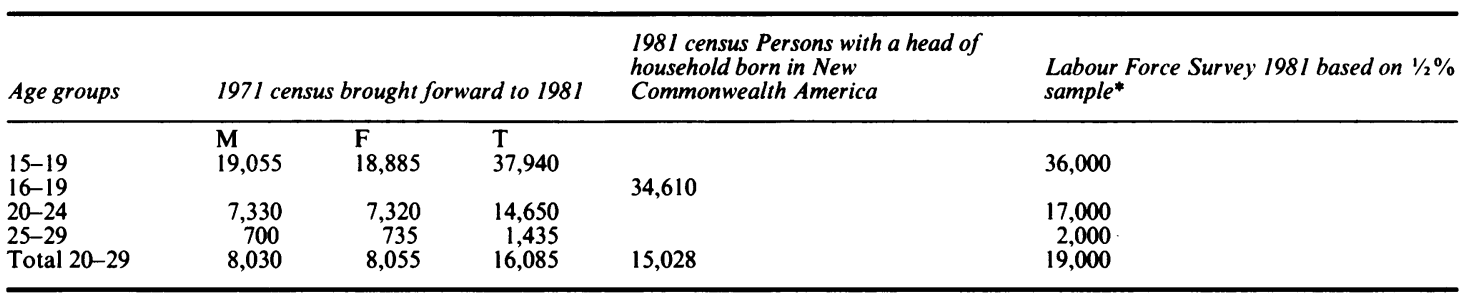

* Rounded to nearest 1,000 as based on small numbers and subject to sampling error.

tarial staff of the neurology departments of the London hospitals. We were permitted to study the hospital case records by the hospital research committees.

A copy of the birth registration to verify the birthplace of these patients was obtained from the Office of Population Censuses and Surveys (OPCS), London, and the patient's doctor confirmed the birthplace of the parents.

\section{Results}

Sixteen United Kingdom-born West Indian patients with probable multiple sclerosis (5 male, 11 female) resident in Greater London with NC American (West Indian)-born parents were found. The analysis of multiple sclerosis incidence and prevalence in this report is based on these 16 patients with probable, or clinically definite, multiple sclerosis.

A patient with a progressive paraplegia, psychiatric symptoms and with oligoclonal bands and increased IgG in the CSF has been diagnosed by the patient's neurologist as possible multiple sclerosis. A further patient was diagnosed as having "bilateral retrobulbar neuritis due to demyelination". All except one of these 18 patients, resident in Greater London, were also born in London. The sex, date and place of birth, hospital where admitted and diagnosed, first symptom, some of the important symptoms and signs and birthplace of the parents, are shown in table 2 (part 1).

Two United Kingdom-born multiple sclerosis patients resident in London were traced with mixed parentage, one with a West Indian father and a Welsh mother and the other an American (United States not NC America) black father and an Irish mother (table 2, part 2). All the patients with probable multiple sclerosis had exacerbations and remissions of symptoms. Two of the West Indian patients had epilepsy and two had symptoms of schizophrenia.

Two London-born black African multiple sclerosis patients with parents born in Ghana were found among the small population $(13,105$ resident Greater London, 1971 census) with parents (black, Asian or white) born in the NC African countries (table 2, part $3)$.

The average annual incidence of multiple sclerosis in the 16 West Indian patients with probable multiple sclerosis is shown in table 3. The time between onset, as described in the case histories, and diagnosis was short. The age at first symptom was in the three age groups, 15-19, 20-24 and 25-29 years. All 16 had their first symptom during the nine years 1976-84 and 13 of the 16 within the five years 1979-83. The average annual incidence has been calculated for the 16 patients over the nine-year period 1976-84, and also for the 13 patients who cluster during the five years 1979-83.

No studies had been reported on the incidence or prevalence of multiple sclerosis in South East England by sex and age group until July $1986 .{ }^{31}$ In Northern Ireland a register of multiple sclerosis patients has been maintained since 1948 and Allison and Millar published in 1954 the annual average incidence rates (rates by age at onset) based on the prevalence in 1951 (table 3). ${ }^{10}$ At that time there were 621 multiple sclerosis patients (476 probable, 145 possible) on the Northern Ireland register and there was a prevalence of probable multiple sclerosis of $35(34 \cdot 7)$ per 100,000 . This was certainly an underestimate by approximately a factor of two because subsequent studies have shown a much higher prevalence $(1,158$ probable + possible multiple sclerosis, 1961). ${ }^{11}$ The calculated prevalence of probable multiple sclerosis in Northern Ireland is much the same as in the Republic of Ireland $(66$ per 100,000$){ }^{12}$ The average annual incidence for probable multiple sclerosis of the United Kingdom-born West Indians is, in the age groups available, of the same order of magnitude as twice the rates reported in Northern Ireland in 1954 (table 3).

April 1, 1984, was chosen as prevalence day. As this is three years after the 1981 census date, the five-year age groups studied were 13-17 (rather than 10-14), $18-22,23-27$ and $28-32$ years. The prevalence rates have been compared with those found in the Republic of Ireland in 1971 when the prevalence of probable multiple sclerosis was $66(65 \cdot 5)$ per $100,000 .{ }^{12}$ That these rates for diagnosed probable multiple sclerosis are of the right order of magnitude has been confirmed by further studies on three small populations each of about 30,000 people. $^{13-15}$ The preva- 
Multiple sclerosis among the United Kingdom-born children of immigrants from the West Indies

Table 2 United Kingdom-born multiple sclerosis patients with New Commonwealth American (West Indian)-born parents

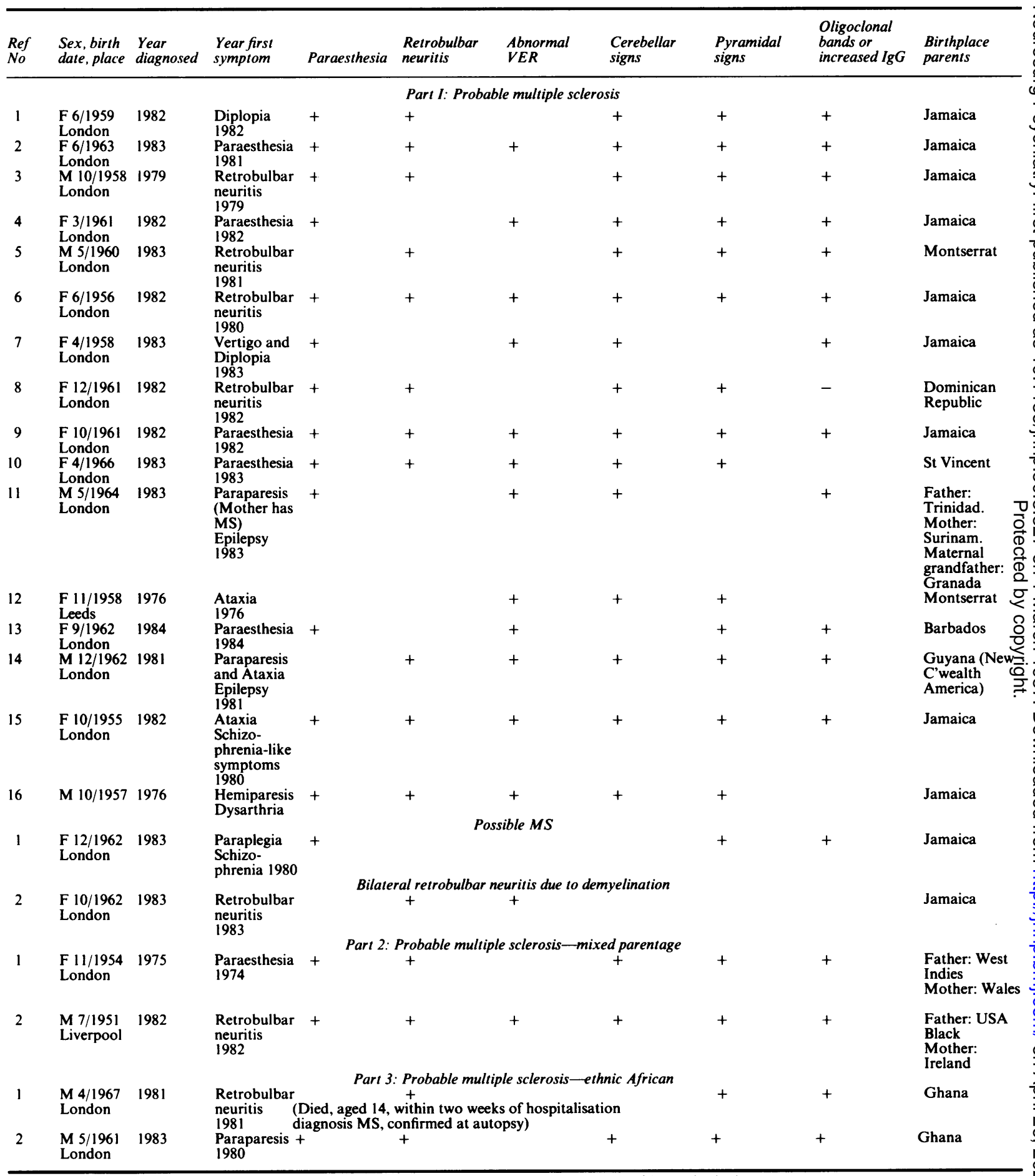

All the probable multiple sclerosis patients had exacerbations and remissions, except the black African who had a necropsy. 
Table 3 Average annual incidence of patients diagnosed as having probable multiple sclerosis among the Greater London-born children of West Indian-born parents, resident in Greater London, 1976-84

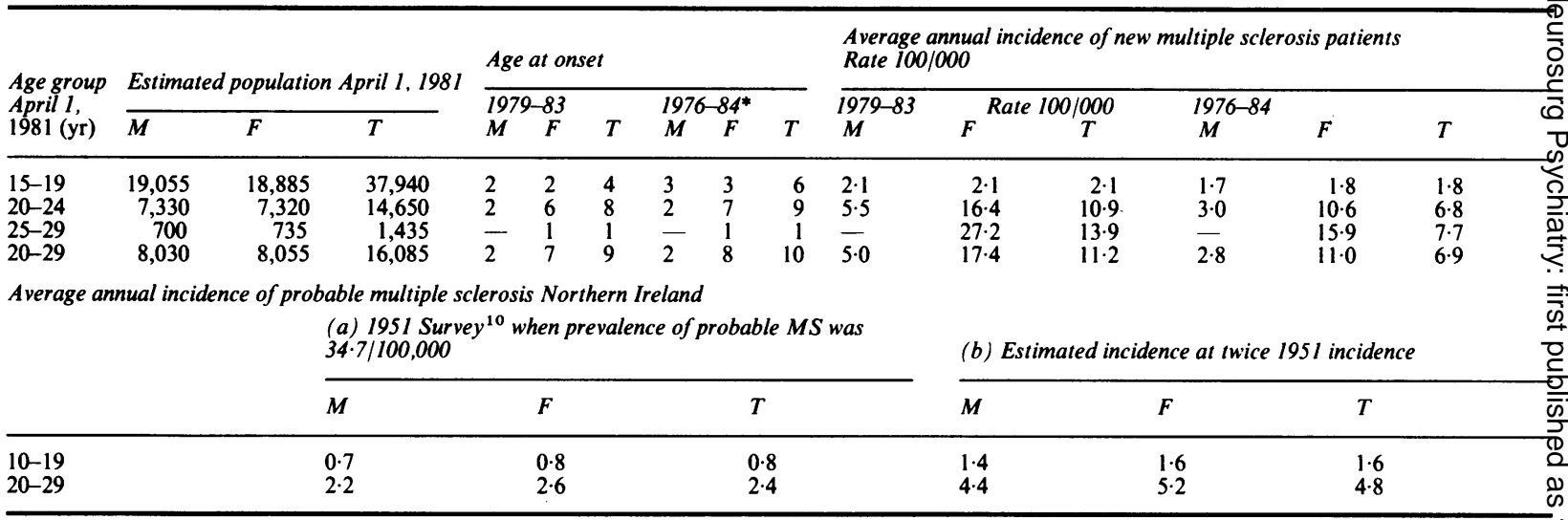

*Patients 12 and 16, diagnosed 1976, and patient 13 diagnosed 1984 are included in the 9-year period.

lence rates for the United Kingdom-born children of West Indian immigrants are similar to the rates in the Republic of Ireland in the age groups available for study. A very recent study in a South London borough showed a prevalence of probable and possible multiple sclerosis in the age groups $15-24 \mathrm{yr}$ of 20/100000, and in the age group 25-34 yr $122 / 100000$.

\section{Discussion}

In ascertaining the incidence and prevalence of multiple sclerosis in the United Kingdom-born children of West Indian immigrants there were three major difficulties. The first was that a question on the birthplace of parents was not included in the 1981 census but only in the 1971 census so that the 1981 popu- lation had to be estimated. The 1971 census, judging by checks undertaken by the Office of Population Censuses and Surveys, London, may have underestimated the population by varying amounts between $1 / 2 \%$ and $21 / 2 \%$. On the other hand, no account has been taken in the estimate of the 1981 population of deaths between 1971 and 1981. Evidence that there was little significant inward movement of the relevant population is that 17 of the 18 West Indian patients with probable or possible multiple sclerosis in this study were born in London.

The second difficulty was in finding the multiple sclerosis patients as they could not be distinguished by their names in the case records. It is likely that a few have been missed, particularly before 1979, which explains why the annual incidence rates, 1979-83, are so much higher than the average annual incidence 1976-84. It is of interest that the majority of the West

Table 4 Probable multiple sclerosis among children of West Indian-born parents born and resident in Greater London by cohort and age group

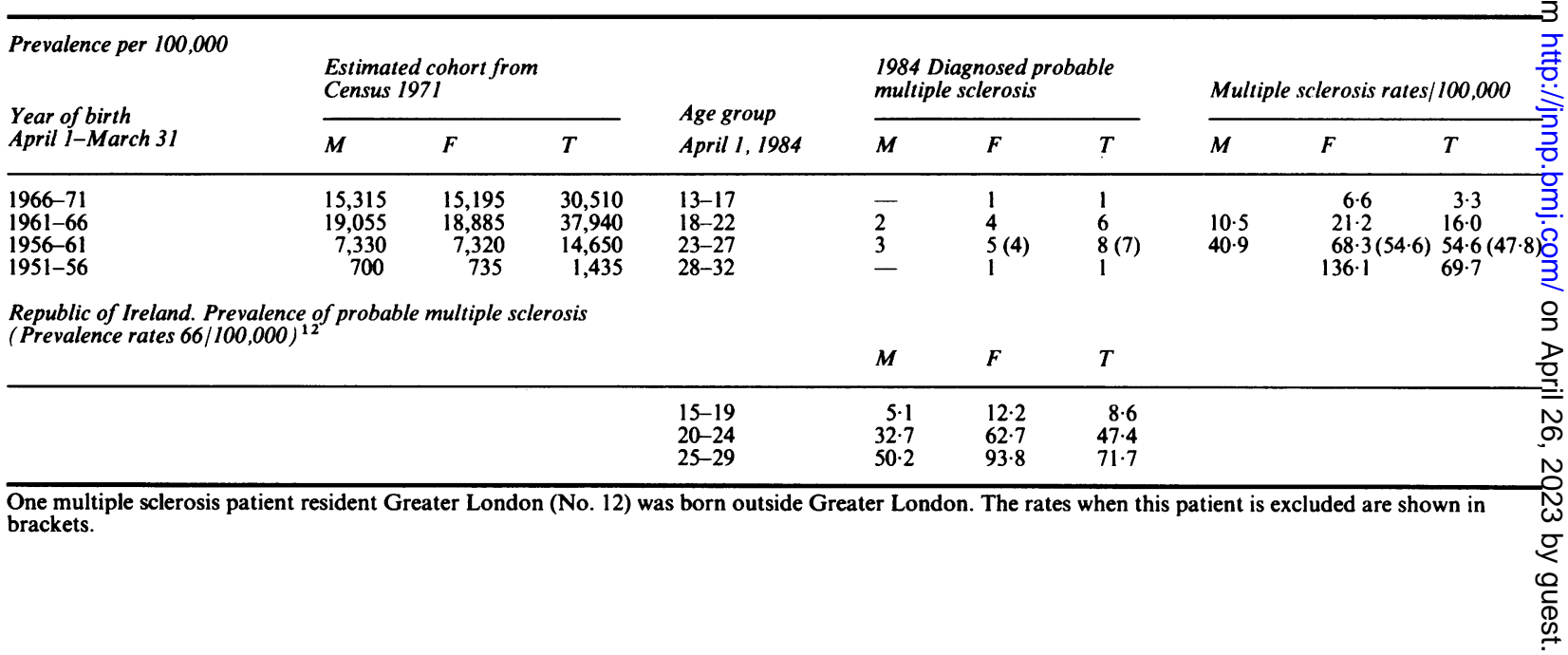


Indian patients in this study with probable multiple sclerosis had unusually severe symptoms and clear physical signs with a relatively short time between onset and diagnosis. This suggests that there may be a number of patients with mild multiple sclerosis symptoms in this group who are not yet diagnosed or that multiple sclerosis is unusually acute in these patients.

The third difficulty was the absence of studies in south-east England on the incidence and prevalence of multiple sclerosis by age group with which a comparison could be made. The two studies that would appear to offer the best comparison are those undertaken in Ireland. ${ }^{30-12}$ In the Republic of Ireland the prevalence of probable multiple sclerosis was 66 per 100,000 population in $1971 .{ }^{12-15}$ Irish immigrants to the West Midlands had much the same risk of being hospitalised with multiple sclerosis as expected at the United Kingdom-born rates. ${ }^{6}$ Studies in North East Scotland show a higher multiple sclerosis prevalence ${ }^{16}$ but, judging by the multiple sclerosis mortality rates, the prevalence in Scotland is higher than in England and Wales, where the prevalence is generally estimated to be $50-70$ per 100,000 , although intensive surveys in small populations might well show a higher figure.

Multiple sclerosis among the West Indians, whether they are born in the West Indies or in the United Kingdom, showed a more acute form of the disease with a shorter time interval on average between onset and definite diagnosis than occurs among the United Kingdom-born. Epilepsy and symptoms of schizophrenia were more frequent than expected in these patients.

A subsequent report will analyse the risk of multiple sclerosis among immigrants from the West Indies, Asia and Africa, by age at immigration. Kurtzke has commented that the original report on multiple sclerosis in immigrants resident in London and the West Midlands ${ }^{56}$ was perhaps too early to show the risk of developing multiple sclerosis due to immigrating young and the effect of age at immigration. ${ }^{17}$

The risk of developing multiple sclerosis in the West Indies may be much higher than was previously reported, as happened in Italy ${ }^{18-22}$ and there might be the same high multiple sclerosis prevalence in the West Indies as occurs in the United Kingdom. Cruickshank and Montgomery reported in 1961 that multiple sclerosis was very rare in Jamaica. ${ }^{1}$ They saw only seven multiple sclerosis patients in Jamaica, three of whom were Europeans, between 1951 and 1961 and they have seen a further 10 multiple sclerosis patients in Jamaica between 1961 and $1971 .^{2}$ On the other hand, they have reported a high prevalence of Jamaican neuropathy. Perhaps some of these patients may have had multiple sclerosis and the prevalence may have been underestimated in Jamaica and in the
West Indies generally. The relatively low risk of developing the disease among West Indian immigrants to England is nevertheless strong supportive evidence that the disease is uncommon in the indigenous population of the West Indies.

A subsequent paper will report on the incidence and prevalence of multiple sclerosis in the United Kingdom-born children of Asian and black African immigrant parents. In order to provide a sufficiently large population at risk, this study will be based on the populations at risk in south-east England and in the West Midlands.

Multiple sclerosis among the United Kingdomborn children of West Indian immigrants diagnosed in hospital in London is, in the age groups studied, of the same order of frequency as has been reported in Ulster and the Republic of Ireland. It is necessary to confirm or refute the reported low prevalence of multiple sclerosis in different age groups in the West Indies, say in Jamaica, the country of origin of the parents of most of the United Kingdom-born children of West Indian immigrants. If the prevalence of multiple sclerosis in the West Indies is low, as has been reported, and the prevalence among the United Kingdom-born children of West Indians is high, this means that the risk of multiple sclerosis increases among the United Kingdom-born children of immigrants from that of at least some of the low multiple sclerosis prevalence countries to that of the high prevalence country, England.

Multiple sclerosis has not yet been found among South Africa's 20 million black population. ${ }^{34}$ In the United States in the studies on veterans in which similar standards of care were applied to all races the relative risk of black males as compared with whites was $0 \cdot 4 .^{2324}$ Although the study of multiple sclerosis among United Kingdom-born children of black African-born parents is not yet completed, two such patients, both diagnosed at London hospitals and one of them confirmed at necropsy, have already been found among the small population in this group at risk of developing multiple sclerosis.

Immigrants from high multiple sclerosis prevalence areas, such as Europe, to low prevalence areas, such as South Africa or Israel, keep a high risk of developing the disease unless they migrate in childhood. ${ }^{45-27}$ Their descendants born in the low prevalence country have a lower multiple sclerosis prevalence. Conversely, immigrants from the West Indies, considered to be a low multiple sclerosis prevalence area, to England, a high prevalence area, have a low risk of developing multiple sclerosis, although the effect of age at immigration is still to be reported. Their children born in the United Kingdom have, at least in the age groups studied, a high incidence and prevalence of multiple sclerosis. 


\section{Conclusion}

There are now a number of epidemiological studies that show that multiple sclerosis is primarily due to an environmental factor, although there is some evidence that predisposition also plays a part. The evidence now includes the epidemic of multiple sclerosis among the seven, or eight, research workers into swayback disease in North Derbyshire, ${ }^{28}{ }^{29}$ the high prevalence among immigrants from Europe to South Africa or Israel unless they migrate in childhood, ${ }^{45-27}$ the reported increase in the prevalence of multiple sclerosis after the occupation of the Faroe Islands during the 1939-45 war $^{30}$ and, in confirmation, the increase in incidence and prevalence of multiple sclerosis in the children of West Indian immigrants born in England reported here.

We thank all those who have assisted us with this study, in particular the neurologists, medical registrars, senior medical officers and their secretaries at the London hospitals and the staff of the medical records departments. We also thank Mrs Margaret Lane of the Office of Population Censuses and Surveys, and Mr DW Down of the Department of Environment, London, for their assistance with the populations at risk and Miss Hilda McLoughlin for assistance with the preparation of the tables and the paper.

This study was supported by a grant from the Multiple Sclerosis Society of Great Britain and Northern Ireland.

\section{References}

1 Cruickshank EK, Montgomery RD. Multiple sclerosis in Jamaica. W Ind Med J 1961;10:211.

2 Spillane JD. Tropical Neurology, 1983. Oxford University Press.

3 Matthews WB, Acheson ED, Batchelor JR, Weller RO. McAlpines Multiple Sclerosis. Edinburgh: Churchill Livingstone, 1985.

4 Dean G. Annual incidence, prevalence and mortality of multiple sclerosis in white South African-born and in white immigrants to South Africa. $\mathrm{Br} M e d \mathrm{~J}$ 1967;2:724-30.

5 Dean G, McLoughlin H, Brady R, Adelstein AM, Tallett-Williams J. Multiple sclerosis among immigrants in Greater London. Br Med J 1976;1:861-4.

6 Dean G, Brady R, McLoughlin H, Elian M, Adelstein AM. Motor neurone disease and multiple sclerosis among immigrants to Britain. Br J Prev Soc Med 1977;31, 3:141-7.

7 The Country of Birth, Great Britain, Census 1971. London: Office of Population Censuses and Surveys.

8 The Country of Birth, Great Britain, Census 1981. London: Office of Population Censuses and Surveys.

9 Labour Force Survey, 1981. London: Department of Environment.

10 Allison RS, Millar JHD. Prevalence and familial incidence of disseminated sclerosis. Ulster Med J 1954;23, Suppl 20.
11 Millar JHD. Multiple sclerosis in Northern Ireland. In: Clifford RF, ed. Clinical Neuroepidemiology. Pitman Medical, 1980.

12 Brady R, Dean G, Secerbegovic S, Secerbegovic AM. Multiple sclerosis in the Republic of Ireland. Ir Med J 1977;70, 71:500-6.

13 Beckett A. The prevalence of Multiple Sclerosis in Co. Tipperary. Dublin: The Multiple Sclerosis Society of Ireland, 1983.

14 Hutchinson M. Disability due to multiple sclerosis: a community based study of an Irish county. Dublin: The Multiple Sclerosis Society of Ireland, 1985.

15 Tubridy J. The social and economic circumstances of people with Multiple Sclerosis in counties Carlow and Kilkenny. Dublin: The Multiple Sclerosis Society of Ireland, 1985.

16 Shepherd DI, Downie AW. A further prevalence study of multiple sclerosis in north-east Scotland. J Neurol Neurosurg Psychiatry 1980;43:310-5.

17 Kurtzke JF. Multiple sclerosis among immigrants. $\mathrm{Br}$ Med J 1976;1:1527-8.

18 Dean G, Grimaldi G, Kelly R, Karhausen L. Multiple sclerosis in southern Europe I: Prevalence in Sicily in 1975. J Epid Commun Hlth 1979;33:107-10.

19 Savettieri G, Daricello B, Giordano D, Karhausen L, Dean G. The prevalence of multiple sclerosis in Sicily. I: Monreale city. J Epid Commu Hlth 1981;35:114-7.

20 Dean G, Savettieri G, Giordano D, et al. The prevalence of multiple sclerosis in Sicily. II: Agrigento city. J Epid Commu Hlth 1981;35:118-22.

21 Morganti G, Naccarato S, Elian M, et al. Multiple sclerosis in the Republic of San Marino. J Epid Commun Hlth 1984;38:23-8.

22 Savettieri G, Elian M, Giordano D, Grimaldi G, Ventura A, Dean G. A further study on the prevalence of multiple sclerosis in Sicily: Caltanissetta city. Acta Neurol Scand 1986;73:71-5.

23 Kurtzke JF, Beebe GW, Norman JE. Epidemiology of multiple sclerosis in US veterans I. Race, sex, and geographic distribution. Neurology 1979;29:1228-35.

24 Norman JE, Kurtzke JF, Beebe GW. Epidemiology of multiple sclerosis in US veterans 2. Latitude, climate and the risk of multiple sclerosis. J Chron Dis 1983;36:551-60.

25 Dean G, Kurtzke JF. On the risk of multiple sclerosis according to age at immigration to South Africa. $\mathrm{Br}$ Med J 1971;3:725-9.

26 Alter M, Leibowitz U, Speer J. Risk of multiple sclerosis related to age at immigration to Israel. Archs Neurol 1966;15:234-7.

27 Alter M, Kahana E, Loewenson R. Migration and risk of multiple sclerosis. Neurology 1978;28:1089-93.

28 Campbell AMG, Daniel P, Porter RJ, Russell WR, Smith HV, Innes JRM. Disease of the nervous system occurring among research workers on swayback in lambs. Brain 1947;70:50-8.

29 Dean G, McDougall EI, Elian M. Multiple sclerosis in research workers studying swayback in lambs: an updated report. J Neurol Neurosurg Psychiatry 1985;48:859-65.

30 Kurtzke JF, Hyllested K. Multiple sclerosis in the Faroe Islands: I: Clinical and epidemiological features. Ann Neurol 1978;v:6-21.

31 Williams ES, McKeran RD. Prevalence of multiple sclerosis in a South London borough. $\mathrm{Br} \mathrm{Med} J$ 1986;2:237-9. 